\title{
Surdez, redes sociais e proteção social
}

\author{
Deafness, social network and social protection
}

ZéliaZilda Lourenço deCamargo Bittencourt ${ }^{1}$

M aria de Fátima de Campos Françozo ${ }^{1}$

Claudia Rodrigues $\mathrm{M}_{\text {onteiro }}{ }^{1}$

Débora DuranteFrancisco ${ }^{1}$

${ }^{1}$ Centro de Estudose Pesquisas em Reabilitação Prof. Dr. Gabriel Oliveira daSilva Porto, Faculdade deCiências M édicas, Universidade Estadual de Campinas. Rua Tessália Vieira de Camargo 126 Cidade Universitária. 13084-971 Campinas SP. zeliaz@fcm.unicamp.br
Abstract Deafness brings consequences to deaf people's lifeas well as to their families, who usually has its dynamic changed in thestruggleto adapt to the new needs and demands. In this sense, the families not only use their internal resources, but also, they look for help and support out of their group, in their social network. The goal of this paper is to describe the social network used by families with a deaf member in their everyday life. Also, it discusses the meaning of these networks in the framework of social protection. A qualitative research was developed, using a semistructured interview to collect data. Eighteen parents of deaf children or teenager assi sted at a center of rehabilitation were interviewed. M apping the networks of relationships and social resources that the families of a deaf person use to deal with deafness showed the interconnection between family members, other relatives, friends, neighbors, professionals, private and public services. The networks play an important role of support and social protection to the deaf person's family in the everyday life. Key words Social network, D eafness, Social protection, Family
Resumo A surdez traz repercussões na vida do indivíduo que por ela é afetado, assim como na vida da família, que usualmente deve modificar sua dinâmica para adequar-se às necessidades e demandas que a perda auditiva impõe. M uitas vezes, para isso, a família mobiliza recursos internos, mas também busca apoio e ajuda fora de seu núcleo, em uma rede de recursos externos. D escrever as redes sociais acessadas pelas famílias de surdos na busca de sua reprodução cotidiana é um dos objetivosa que estetexto se propõe. Ainda, busca discutir o significado dessas redes no contexto da proteção social. Para isso, pesquisa qualitativa foi desenvolvida, através de entrevistas se miestruturadas com dezoito pais de crianças ou adolescentes surdos, usuários de programas de atendimento em um centro de reabilitação. 0 mapeamento das redes de relacionamentos e de recursos sociais acessados por famílias de pessoas surdas mostrou 0 entrelaçamento de relações entre os familiares, demais parentes, amigos, vizinhos, profissionais, organizações privadas e serviços públicos. As redes cumprem papel de apoio e proteção social para a família da pessoa surda na reprodução cotidiana da vida.

Palavras-chave Redes sociais, Surdez, Proteção social, Família 
Introdução

Há no mundo quinhentos milhões de pessoas com al guma deficiência, das quais $80 \%$ vivem em países em desenvolvimento. Apesar de esforços da Organização Mundial de Saúde (OMS) no sentido de difundir formas para prevenir ou atenuar os vários tipos de deficiência, no Brasil, aproximadamente $10 \%$ dos brasileiros são portadores de deficiência mental, motora ou sensorial $^{1}$. Em relação à deficiência auditiva, a prevalência de crianças com perda congênita, profunda, bilateral e sensorioneural é de 1:1000 nascidos vivos e a de crianças com indicadores de risco com perda auditiva moderada, severa ou profunda de $6: 1000^{2}$. A incidência de perda auditiva em crianças em berçário normal é de 3:1000 e de crianças em UTI neonatal é de 23:10003.

Dados da OMS informam que $40 \%$ das gestantes têm alguma complicação no decorrer da gravidez e $15 \%$ destas necessitam cuidados específicos para a diminuição do risco de vida para a mãe ou a criança. No Brasil, $36,5 \%$ dos casos de crianças com deficiência auditiva devem-seà intercorrências na gestação ${ }^{4}$.

Em nosso meio, a deficiência auditiva tem sido diagnosticada por volta de dois a três anos de idade, sendo que até este período a criança já perdeu informações auditivas importantes, alterando o processo de comunicação. 0 diagnóstico precoce possibilita a orientação da família no que se refere à comunicação, minimizando ou até eliminando os prejuízos causados pela falta de informação auditiva 5 .

As últimas décadas trouxeram importantes conquistas no campo dos direitos sociais, recriando o conceito de cidadania e associando a ela novos temas e novas dimensões ${ }^{6}$. Tais conquistas se refletiram na área da surdez, imprimindo um novo paradigma na questão da identidade do surdo como reconhecimento político da surdez enquanto diferença. N estecontexto, a surdez deixa deser vista como deficiência eo surdo passa a ser reconhecido como parte de uma minoria linguística ecultural?.

Em termos do exercício de direitos, a Constituição de 1988, imprimiu profunda transformação no padrão de proteção social brasileiro, inaugurando um período em busca da universalização da cidadania ${ }^{8}$. Estes avanços se refletiram na implementação de políticas públicas em diversas áreas, em especial naquelas que dizem respeito à proteção social, ou seja, saúde, previdência e as- sistência social etambém no campo da educação. A proteção social destina-se à população quevive em situação de vulnerabilidade social decorrente da pobreza, privação e/ou fragilização de vínculos afetivos, como discriminações etárias, étnicas, de gênero ou por deficiências entre outras?.

$\mathrm{Na}$ área da saúde, os direitos da pessoa surda vão se consolidando, visto a magnitude eimpacto social da deficiência auditiva na população brasilei ra esuas consequências, culminando com a instituição da Política Nacional de Atenção à SaúdeAuditiva (Portaria n 2.073 de28/09/2004). Tal política prevê o desenvolvimento de estraté gias de promoção da qualidade de vida, educação, proteção e recuperação da saúde e prevenção de danos, protegendo e desenvolvendo a autonomia e equidade de indivíduos e coletividades, organizando cuidados integrais com assistência multiprofissional einterdisciplinar.

$\mathrm{Na}$ área da assistência social, a Lei Orgânica da Assistência Social - LOAS (Lei no 8.742 de 07 / 12/1993) prevê o Benefício de Prestação Continuada (BPC) àquelas pessoas com deficiência cuja família não tem como prover suas necessidades em função de renda insuficiente. Representa a garantia de um salário mínimo mensal à pessoa portadora de deficiência e ao idoso que comprovem serem incapazes de prover a sua manutenção ou têla provida por sua família.

A despeito destes avanços legais, sabe-se que os direitos sociais são difíceis de se materializar em compromissos entre o Estado e a sociedade, e não garantem sua imediata implementação. Assim, a cidadania enfrenta tensões paradoxais, necessitando mecanismos da sociedade para fazer valer tais direitos e romper com certos preconceitos ligados a este grupo populacional.

Neste sentido, famílias com pessoas surdas buscam superar as barreiras impostas pela deficiência auditiva, valendo-se de recursos variados e com maior ou menor sucesso na empreitada. Para os profissionais que trabalham com essas famílias, torna-se necessário conhecer como os pais e demais familiares são afetados e como lidam com as repercussões e demandas ligadas à situação da perda auditiva. Pensar esta questão remete à proteção social, seja ela relacionada ao Estado ou à sociedade civil. N este trabalho, a questão da surdez e a proteção social serão discutidas a partir das redes sociais que compreendem tanto os relacionamentos como os recursos utilizados cotidianamente pelasfamílias queconvivem com a surdez. 


\section{Redes sociais}

As relações do sujeito com seu meio social envolvem processos dinâmicos, que requisitam contínuas adaptações. Inúmeros recursos são mobilizados para suprir as necessidades de reprodução cotidiana, ou seja, a maneira pela qual possa garantir-se o mínimo necessário à sobrevivência individual ou de um grupo doméstico. Dessa maneira, 0 arranjo de redes sociais apresenta-se como um dos recursos fundamentais.

Investigações correlacionando redes sociaise famílias há tempos são pautadas em diversos campos de estudo, tais como a antropologia, sociologia e psicologia e interessam a pesquisadores na tentativa de se compreender seu impacto sobre a vida social. Os conceitos desses termos são usualmente tributários de permanentes discussões nas ciências sociais ${ }^{10}$.

A idéia de rede admite a complexidade do social, constituída por atores e organizações heterogêneas, nas quais além do conflito existente em razão do grande número de contradições, opera também o princípio da solidariedade. Este pode ser compreendido como fundamento ético na construção de inúmeras redes, significando responsabilidade com o bem comum, unindo interesses individuais e coletivos ${ }^{11}$.

A metáfora rede diz respeito a sistemas sem barreiras, articulado por nós e elos, representados por sujeitos sociais (indivíduos, grupos, organizações, etc.) que unem objetivos e recursos em torno de interesses e valores comuns ${ }^{10}$.

Fernandes ${ }^{12}$ discutea equivalência das unidades que compõem a rede, não havendo entreelas hierarquia e centralidade: todas se voltam para si einteragem com as demais, por meio de relações não necessariamente equivalentes, entretanto bem definidas.

A família não é uma totalidade isolada, estando ligada a outros indivíduos e a outros grupos através dos indivíduos que a compõem edos seus relacionamentos ${ }^{13}$. N uma perspectiva seme Ihante, vemos que a família não deve ser compreendida como uma somatória de suas partes, visto que ocorre uma reestruturação do todo quando surge um movimento que afete um dos seus componentes ${ }^{14}$.

Portanto, conforme Bowling, citado por Griep et al..$^{15}$, na dinâmica da sociedade, as redes sociais definem-se como um grupo de pessoas com as quais o indivíduo mantém contato ou al guma forma de vínculo social ou, ainda, como a rede derelacionamentos sociais que envolvem um indivíduo e as características destas ligações. Entre estas, pode-se citar o número de pessoas com as quais interagem a partir de pertencimento familiar, da vizinhança, do trabalho e círculo de amizades; a frequência desses contatos sociais; a forma pela qual se encontra estruturada a família, ser membro de alguma organização e atividades realizadas em grupos.

As redes proporcionam 0 apoio social que ressalta os aspectos positivos das relações sociais, como o compartil lhar informações, o auxílio em momentos de crise e a presença em eventos sociais ${ }^{16}$.

Carvalho ${ }^{17}$ aponta que as sociabilidades sociofamiliares e as redes de solidariedade, para as camadas populares brasileiras, são a condição de resistência e sobrevivência. Esta resistência pode ser transferida para a ótica do enfrentamento de uma deficiência na esfera familiar, assim como de cuidado de longo prazo. Dessa forma, a família inserida numa rede de relacionamentos que une objetivos em torno de anseios comuns, assumindo um compromisso de cuidado mútuo, terá toda sua dinamicidade alterada. Isto resultaria em uma redefinição de papeis, atitudes e valores, caso um fator impactante, como a deficiência auditiva em um deseus membros, venha a afetá-los.

\section{Métodos}

O perfil das famílias entrevistadas

As informações aqui discutidas são resultantes de pesquisas qualitativas realizadas com familiares de usuários surdos de programas de reabilitação, tendo como cenário um centro de reabilitação. Foram entrevistados dezoito sujeitos que aceitaram participar voluntariamente do estudo, respeitando-se o protocolo ético. 0 projeto foi aprovado pelo Comitê de Ética.

Por meio do contato com um membro da família, foi possível delinear al guns traços do perfil familiar e conhecer aspectos da sua estrutura. As entrevistas foram realizadas quase em sua totalidade com mães dos usuários, exceto em um caso, no qual era o pai quem acompanhava o filho aos atendimentos. Os progenitores apresentavam, na sua maioria, união legal ou consensual eencontravam-sena faixa etária entre 26 e 45 anos. Todos os familiares entrevistados eram ouvintes. O sustento financeiro da casa se dava em grande parte pelo marido, provedor de recursos do lar. A maioria das mães não exercia atividades remuneradas, tendo como atividade básica o cuidado da 
família e do lar, sendo figuras centrais no processo de reabilitação do filho surdo. Asfamílias residiam predominantemente na região próxima ao centro de reabilitação. A maioria das famílias não possuía parentes ou outras pessoas morando na mesma residência, sendo considerada nuclear, ou seja, constituída por pai, mãe e filhos. Mais da metade das famílias era composta por quatro a cinco pessoas; portanto, eram famílias pequenas.

No que se refere ao conhecimento do diagnóstico, em mais da metade dos casos, os pais relataram desconhecer totalmente a causa da surdez. Já quanto à informação sobre o grau da surdez de seus filhos, explicaram detalhadamente o grau da perda auditiva (profunda, severa, moderada).

\section{Resultados ediscussões}

Rede de relacionamentos e proteção social

0 mapeamento da rede de relacionamentos das famílias que têm entre seus membros um indivíduo surdo entrelaça os próprios membros familiares, parentes distantes, amigos, vizinhos (mecanismos extradomésticos), com maior ou menor grau deenvolvimento, configurando o que se pode entender, nas palavras de Guimarães ${ }^{18}$, como os canais informais, não institucionais. Já a ajuda de profissionais, vinculados a instituições privadas, serviços públicos, que também aparecem como parte da rede, podem ser chamados de canais formais, institucionais.

\section{Os familiares}

A presença de uma criança surda em uma família de ouvintes gera um impacto importante, pois as relações mútuas e as interações entre os membros da família mudam, exigindo, muitas vezes, de cada membro, redefinições de papéis de maneira a buscar novo equilíbrio $0^{19,20}$. Assim, quando mencionada ajuda por parte de membros da família, esta ocorreu predominantemente entre aqueles que residiam em localidades próximas, configurando um sistema de trocas que inclui o cuidado às crianças, apoio emocional e também, algumas vezes, ajuda financeira. Gerhardt ${ }^{21}$ descreve que quanto mais próximos geograficamente forem os laços de parentesco, mais probabilidade de encontrar o desenvolvimento de estratégia que envolva a rede familiar, enquanto que um distanciamento promove a mobilização de redes comunitárias: Tra- bal hava (a irmã) eeu ficava em casa àsvezesol hando a filha dela, queela tem uma filha também, aí a gente se ajudava. Ela ia trabalhar e eu ficava na casa dela, ol hava a filha dela. Aí depois eu arrumei um trabalho também, comecei a ajudar financeiramente também, aí a gente foi levando.

Quem eu deixo pra ol har quando preciso, que peço alguma ajuda assim é pra minha cunhada. Quando a gente tem parente, assim a gente procura mais os parentes.

Durante o processo de adaptação à situação da deficiência, a avó desempenha papel preponderante no auxílio à família, sendo a primeira pessoa a ser lembrada pelos entrevistados. Nybo et al. ${ }^{22}$ explicam que geralmente os avós fornecem apoio após o diagnóstico da surdez, tendo significativa atribuição ao auxílio afetivo no processo de dissolução das dificuldades: Pra falar a verdade, assim, tem minha mãe, ela tá junto com a gente, é pau pra toda obra, inclusive ela tava com emprego que ela ia ficar com o P. (filho surdo), enquanto que nós duas (referindo-se à outra fiIha) vamos pra aula desinais. Aí a hora quetermina, ela vai embora, então minha mãeéassim, ela é ajuda mesmo.

No tocante ao sistema de trocas, as ajudas referem-se principalmente aos aspectos de apoio e suporte no enfrentamento da surdez e a algum suporte financeiro: Ele (pai) não é muito assim, atéqueeleajuda, mas agora eletá mais ajudando a parte financeira, quando ela (filha) precisa de alguma coisa, fala pra mim falar pra ele, masassim de acompanhar não, deacompanhar, devim aqui não.

Ajuda financeira de material foi essa minha irmã que eu vejo de vez em quando eatéhojeela dá uma força ainda.

A ajuda de amigos, vizinhos

e colegas de trabalho

As ajudas provenientes de canais informais (amigos, vizinhos, colegas de trabalho, clientes) também apareceram como uma das formas de suporte social, fornecendo apoio no cuidado das crianças, nas finanças ou prestando informações: Só na época quefoi pra comprar o primeiro aparelho pra ela que meus irmãos, amigos, turma da fábrica, fizeram uma vaquinha pra comprar o apareho.

As clientes todas me deram o maior apoio, todas eram preocupadas. U m cliente meu falou assim: se vai manda os papéis pra lá ( para obtenção do aparelho), eu vou pagar o dia, a semana como se você tivesse trabalhado, vou pagar pra você ir e pra vocêfica lá. 0 pessoal se mobiliza pra caramba lá no meu trabalho. 
$M$ as, nem sempre a solidariedade entre vizinhança é estabelecida, caracterizando um modo de vida no qual as pessoas não expõem suas dificuldades. Esses dados coincidem com os achados de Guimarães ${ }^{18}$, nos quais se acentua um desaparecimento de um estilo de vida configurado por tranquilidade e confiança, no qual as relações de vizinhança eram próximas a ponto de terem as calçadas como extensões do lar, onde todos se conhecem. As relações de vizinhança são vistas primeiramente de maneira positiva; no entanto, há aqueles que referiram dificuldades nas relações, seja por falta detempo para estabelecer contatos, seja por desconfiança: Não, nunca deixei com ninguém! Se não tiver como, quenem hoje não tinha quem levasse essa aqui (referindo-se à filha) pra escolinha, tive que trazer, mas nunca deixei meus filhos na casa de ninguém, não confio.

\section{Novos relacionamentos}

Algumas vezes são exigidas da família estratégias e ajustamentos para suprir as necessidades do sujeito surdo. Em busca de melhores tratamentos para a surdez, famílias mudaram de cidade, tendo assim queiniciar nova redederelacionamentos: A gente se afastou porque teve que sair de perto deles (família) para vir cá para cuidar do M., porque é melhor pra ele, eu fui correr atrás do que é melhor e lá na minha cidade não tinha recursos, não tinha tratamento.

Dessen e $\mathrm{Braz}^{23}$ explicam que a composição da rede social de apoio, bem como as funções exercidas por seus membros, modifica-se com 0 contexto sociocultural, período histórico, estágio do desenvolvimento do indivíduo e fase da família enquanto grupo, e são alteradas quando há o nascimento de filhos.

\section{Os grupos de pais}

Adicionado à nova rede de relacionamentos, há o grupo de pais de usuários da instituição como uma das formas de ajuda acionadas pelas famílias. Os discursos mencionam que o contato com outros pais que vivenciam situações semeIhantes tem servido como uma das fontes de apoio para minimizar as dificuldades da chegada de um membro surdo na família. Por meio de laços de amizade e cumplicidade que se firmam com os contatos semanais entre eles, os sistemas de trocas configuram-se tanto no âmbito emocional, de apoio como também na orientação a recursos sociais. N essas situações, eles dizem com- partilhar sentimentosedificuldades, experiências de vida, informação sobre a surdez e sobre benefícios a serem buscados, sendo esta uma forma de amenizar o sofrimento: Eu converso bastante com elas (outras mães). Elas dizem: vai atrás menina, que tu vai conseguir. Aí quando uma tinha conseguido no advogado, ela meindicou ele, ela me levou lá. É bom que elas conversam bastante comigo, me dá força também. Às vezes eu tô quase desanimando e elas: não menina, não desanima não, vai dar certo!

A importância desta partilha de experiências trazida por alguns pais é apontada também em al guns estudos ${ }^{20,24}$ que mencionam que este contato contribui para uma maior aceitação mútua da surdez, tanto para aquele que oferece a ajuda, quanto para quem a recebe. Boscolo e Santos ${ }^{25}$ afirmam sobre 0 incentivo à formação de grupos de pais como maneira de apoio e local de troca de experiências, que poderá de alguma forma oferecer solidariedade àqueles pais que enfrentam situações similares.

\section{Os profissionais}

Como parte dos canais formais, encontramse os profissionais da saúde que participam da rede de relacionamentos das famílias desde 0 momento em que se instala a suspeita da surdez, durante a confirmação do diagnóstico e permanecem, muitas vezes, ao longo de toda história do sujeito surdo, atuando seja no âmbito educacional, terapêutico ou assistencial. Rodrigues e Pires ${ }^{20}$ ressaltam a importância do papel que os profissionais exercem na vida da criança e da família, uma vez queéatravés dos conhecimentose informações transmitidos por eles que as famílias fazem suas escolhas. H ouve pais que referiram não ter buscado outros auxílios por julgarem acoIhedoras e suficientes as informações e apoios dados pelos profissionais (assistentes sociais, psicólogos, fonoaudiólogos), os quais muitas vezes tornam-se referências para eles na instituição:

Eu procurei assistente social, porque toda vida eu procuro. Aí eu fui lá ela deu uma força grande, a única que eu conto é com a assistente social.

A rede de relacionamentos oferece uma maIha de proteção social, servindo em vários campos: no cuidado das crianças, na ajuda financeira, na orientação e no apoio emocional. O bviamente, depende das características pessoais e familiares para que esta rede se constitua de fato como al go de efetiva proteção - depende das trocas existentes entre as pessoas queformam a rede. 
Rede de recursos sociais e proteção social

Os primeiros recursos buscados pelas famílias em termos de proteção social foram os da área de saúde e de reabilitação com vistas ao tratamento propriamente. $\mathrm{N}$ o geral, nessas mesmas instâncias, são encaminhados para a obtenção deben efícios assistenciaise, dependendo do caso, para instituições educacionais.

Situação recorrente nas falas dos entrevistados foi a descrença nos recursos públicos e a morosidadena obten ção derecursos sociais. Dentre os recursos específicos para pessoas com deficiência, os mais apontados foram o transporte gratuito, doação de prótese auditiva e benefício de prestação continuada. Outros benefícios também demandados pelas famílias foram os programas bolsa-escola, bolsa-família e al guns tipos de auxílios oferecidos pelas prefeituras.

\section{Transportegratuito}

A Legislação Federal (Lei no 8.899 de 2906/ 1994) concede às pessoas portadoras de deficiência o passe livre no sistema de transporte coletivo interestadual, ficando sob vigência de lei estadual e municipal os passes intermunicipais e municipais. 0 transporte para a locomoção até as instituições foi uma das dificuldades mais evidentes relatadas pelas famílias, sendo que a maioria utilizava o transporte gratuito. Algumas famílias ainda aguardavam a solução de entraves burocráticos para obtenção do passe, entraves esses muitas vezes referentes à própria comprovação da deficiência: A assistentesocial falou tudo sobre a carteirinha, aí eu fui atrás, acho que foi trinta dias pra dar entrada nos papéis, tudo o que eles pedem e mais vinte dias pra vir a carteirinha.

A carteirinha do ônibus eu tenho, porque não teria como eu vir aqui.

\section{O Benefício de Prestação Continuada} (BPC)

Muitas famílias não tinham clareza quanto ao BPC, que era confundido como uma aposentadoria para deficientes ou compreendido como direito de todas as pessoas com alguma deficiência, independente derenda. Algumasfamílias referiram que o BPC Ihes foi negado, desconhecendo as razões para tal: Eu tô recebendo faz poucos meses. Foi muito difícil conseguir. Eu tentei duas vezes, sofri muito em fila de IN PS pra conseguir, quando chegava na hora o perito não dava 0 direito pra ela. Entrei com recurso, fiquei um ano esperando, aí o recurso foi negado novamente, aí eu já tinha procurado uma advogada. Ela deu entrada, o perito negou o beneficio, aí ela tentou novamente, aí ela conseguiu. Só quefoi muito difícil.

Foi que nem o benefício que ela tem direito e eu não consegui atéhoje. Já dei entrada uma vez, e o médico nem sequer olhou pra cara dela eindeferiu. Ele perguntou se ela andava, eu falei que andava, perguntou se ela, claro não é débil mental. Simplesmente indeferiu.

Tal benefício tem se mostrado importante mecanismo para a sobrevivência de al gumas famílias, sendo em alguns casos, a única renda familiar: Auxilia bastante. Até hoje ajuda bastante, como meu marido não tem trabalho fixo, quando aparece, aparece. Q uando não aparece, nossa, ajuda bastante mesmo. Até mesmo assim, ele ajudou pra reabilitação dela, mas em muitos casos aténa alimentação da gente.

\section{A prótese auditiva}

A prótese auditiva é um dos recursos tecnológicos para amplificar os sons, fornecendo ao usuário a acessibilidade aos sons da fala audível para, dependendo da perda auditiva, viabilizar o desenvolvimento e manutenção da oralidade ${ }^{26}$. Algumas famílias tiveram acesso à prótese auditiva através de doação, relatando as dificuldades para obtêla. Outros referiram ter comprado a prótese com a própria renda ou utilizando-se de outros expedientes como organização de eventos para arrecadação de fundos, a busca de organizações não governamentais e associação de pais: A médica falou que o aparelho era muito caro. Aí eu falei: muito caro o que? Se eu vender a minha casa dá para comprar?

Consegui 0 aparel ho através da A pascamp. Um foi doado e o outro foi pago. 0 médico, fez um exame, falou vamos conseguir, vamos por um aparelho, vamos fazer um aparelho nela. A gora vai ter o retorno. N ossa, melhorou! Ela tá conseguindo escutar, se comunicar com as pessoas,assim, muitas coisas não entendem ainda, mas tá melhor.

Só a $A$. (ONG) quando eu preciso de lá, pra fazer molde do aparelho, pra fazer audiometria.

A descrença nos programas e políticas sociais é fator que desmotiva a busca por recursos e benefícios: Partido político? Sindicato? (balançou a cabeça dizendo que não) Já procurei a prefeitura mas pra conseguir dinheiro pra ir pra outra cidade (para fazer a prótese), conseguir émuito difícil, tá louco. Só dá canseira.

A pouca utilização dos recursos, no entanto, acaba sendo perda de oportunidade para am- 
pliar também a rede de relacionamentos. Como explica M elman 27: Quando pensamosem rede, não devemos esquecer que os vínculos interpessoais que se estabelecem no cotidiano dos serviços de saúde também passam a fazer parte dessa trama. A multiplicidade de pessoas e relações que compõem uma instituição pode gerar um grande mercado de possibilidades para a tessitura deuma redemaior, mais forte, com mais nós, capaz de gerar mais possibilidades, mais suporte afetivo e material, melhorando a qualidade de vida de todas as pessoas participantes do processo.

A rede de recursos sociais configurou-secomo uma malha flexível, vazada, não suficientemente conhecida ou utilizada pela população. Presta-se como fonte de proteção social, especialmenteem termos de ben efícios às pessoas com deficiência, mas não de forma ampla, universal. Depende muitas vezes do esforço individual efamiliar eda insistência daqueles que requerem benefícios ou direitos.

\section{Consideraçõesfinais}

Embora a família tenha sofrido transformações em suas características, funções e dinâmica, ain- da hoje cumpre papel fundamental no cuidado, proteção e bem-estar de seus membros.

0 mapeamento da rede de relacionamentose de recursos sociais acessados por famílias de pessoas surdas evidenciou o entrelaçamento de relações entre os familiares, demais parentes, amigos, vizinhos, profissionais, organizações privadas e serviços públicos.

A rede cumpre papel de apoio e proteção social para a família em sua busca de qualidade de vida para a pessoa surda ena reprodução cotidiana da vida, estabelecendo uma teia de solidariedade social que substitui algumas intervenções do Estado. A poia-se mais frequentemente nas relações pessoais (familiares, de vizinhança ou de amizade) que na rede de recursos sociais públicos, traduzida nos direitos e ben efícios sociais. Estes últimos são pouco acessados, seja pela falta de informação ou ainda pelas dificuldades em sua obtenção. Em consequência, há um descrédito nas políticas públicas.

Este estudo mostrou a importância de que profissionais da saúde utilizem estratégias eações orientadas para o fortalecimento das redes sociais de apoio e proteção social, apontando, também, para a necessidade da ampliação do acesso às informações com vistas à autonomia das pessoas surdas e suas famílias em seu cotidiano.

\section{Colaboradores}

ZZLC Bittencourt e M FC Françozo trabalharam igualmente na concepção teórica da pesquisa, na orientação das alunas nas diferentes etapas de desenvolvimento da pesquisa e na redação final do artigo. CR M onteiro eDD Francisco procederam à coleta de dados, categorização eanálise dos dados e colaboraram na redação do texto final.

\section{Agradecimentos}

Este trabal ho teve o apoio do CN PQ que concedeu bolsas de iniciação científica às alunas Débora Durante Francisco (PIBIC) e Claudia Rodrigues M onteiro (SAE e PIBIC). 


\section{Referências}

1. Neri M. Diversidade: retratos da deficiência no Brasil. Rio de Janeiro:FGV/IBRE/CPAS; 2003.

2. Hayes D, Northern J. Foreword. In: Hayes D, Northern J, editors. Infants and hearing. San Diego, CA: Singular Publishing Group Inc.; 1996. p. 3-28.

3. White KR, Vohr BR, Behrens TR. Universal newborn hearing screening using transient evoked otoacoustic emissions: results of the Rhode Island assessment project. Seminars in Hearing 1993; 14:18-29.

4. Nobrega M. Aspectos diagnósticos e etiológicos da deficiência auditiva em crianças e adolescentes [dissertação]. São Paulo (SP): Escola Paulista de M edicina; 1994.

5. Marone M R, Lichtig I, M arone SAM. Recém-nascidos gerados por mães com alto risco gestacional estudo das emissões otoacústicas produtos de distorção e do comportamento auditivo. Rev Brasi Otorrinolaringologia 2002; 68(2):230-237.

6. Nogueira MA. O desafio de construir e consolidar direitos no mundo globalizado. Serviço Social \& Sociedade 2005; 82:5-21.

7. Skliar C. A localização política da educação bilíngue para surdos. In: Skliar C, organizador. Atualidade da Educação bilíngue para surdos. Vol. 2. Porto Alegre: Mediação; 1999. p. 7-14.

8. Teixeira SF. Estados sem cidadãos. Rio de Janeiro: Fiocruz; 1997.

9. Secretaria do Estado da Família e da Assistência Social. [acessado 2006 set 01]. Disponível em: http:// www.assistenciasocial.rj.gov.br/pages/prot_soc_bas

10. M arteleto RM. Análise de redes sociais: aplicação nos estudos de transferência da informação. Ciência da Informação 2001; 30(1):71-81.

11. Scherer-Warren I. Redes de movimentos sociais. São Paulo: Loyola; 1996.

12. Fernandes MMLBL. Sobre a rede: olhar de novo um problema velho. Debates Sociais CBCISS 1990; 48/49:23-34.

13. Bott E. Família e rede social. $2^{\underline{a}}$ ed. Rio de Janeiro: Francisco Alves; 1976.

14. M ioto RCT. Família e saúde mental: contribuições para reflexão sobre processos familiares. Katálysis 1998; 2:20-26.

15. Griep RH, Chor D, Faerstein E, Lopes C. Confiabilidade teste-reteste de aspectos da rede social no Estudo Pró- Saúde. Rev Saude Publica 2003; 37(3):379-385

16. Andrade GRB, Vaitsman J. Apoio social e redes: conectando solidariedade e saúde. Cien Saude Colet 2002; 7(4):925-934.
17. Carvalho M CB. O lugar da família na política social. In: Carvalho MCB, organizador. A família contemporânea em debate. 4a ed. São Paulo: Cortez; 2002. p. $15-22$

18. Guimarães IB. Respostas Incertas e Demandas U rgentes na Experiência Popular. Anais do XXVI Encontro Anual da Anpocs. [acessado 2006 jul 20]. Disponível em: http://www.anpocs.org.br/encontro/ 2000/2000.htm

19. Buscaglia L. Os deficientes e seus pais. 4a ed. Rio de Janeiro: Record; 2002.

20. Rodrigues AF, Pires A. Surdez infantil e comportamento parental. Análise Psicológica 2002; 20(3):389400.

21. Gerhardt TE. Situações de vida, pobreza e saúde: estratégias alimentares e práticas sociais no meio urbano. Cien Saude Colet 2003; 8(3):713-726.

22. Nybo WL, Scherman A, Freeman PL. Grandparents' role in family systems with a deaf child: An exploratory study. American Annals of the Deaf 1998; 143(3):260-267.

23. Dessen MA, Braz MP. Rede Social de Apoio durante transições familiares decorrentes do nascimento de filhos. Psicologia: Teoria e Pesquisa 2000; 16(3):221-231.

24. Hintermair M. Hearing impairment, social networks, and coping: The need for families with hearingimpairment children to relate to others parents and to hearing-impairment adults. American Annals of the Deaf 2000; 145(1):41-54.

25. Boscolo CB, Santos TM. A deficiência auditiva e a família: sentimentos e expectativas de um grupo de pais de crianças com deficiência de audição. Distúrbios da Comunicação 2005; 17(1):69-75.

26. Couto MIV, Lichtig I. Amplificação e re(habilitação): direitos e necessidades das crianças surdas. Anais do II Seminário ATIID, acessibilidade, TI e inclusão digital. [acessado 2006 nov 08]. Disponível em: http://www.fsp.usp.br/acessibilidade

27. M elman J. Família e doença mental - repensando a relação entre os profissionais de saúde e familiares. São Paulo: Escrituras; 2001

Artigo apresentado em 03/10/2008

Aprovado em 30/04/2008

Versão final apresentada em 28/05/2009 